\title{
EXISTE VIOLÊNCIA SEM AGRESSÃO MORAL?*
}

\author{
Luís Roberto Cardoso de Oliveira
}

A Roberto Cardoso de Oliveira, in memoriam, com admiração, carinho e saudade.

Inicio este texto com uma provocação a respeito da noção de violência: pode-se falar em violência quando não há agressão moral? Embora a violência física, ou aquilo que aparece sob este rótulo, tenha uma materialidade incontestável e a dimensão moral das agressões (ou dos atos de desconsideração à pessoa) tenha um caráter essencialmente simbólico e imaterial, creio que a objetividade do

* Trabalho apresentado em "Estado, Violência e Cidadania na América Latina: Jornadas Interdisciplinares”, realizadas na Freie Universität Berlin, Alemanha, entre 23 e 25 de junho de 2005. A versão original tinha como título "Direitos, insulto e cidadania: existe violência sem agressão moral?". Agradeço ao convite de Ruth Stanley, assim como seus comentários e dos demais colegas durante o evento. Agradeço também às leituras de Roberto Cardoso de Oliveira, Caetano Araújo, e Carlos Gomes de Oliveira.

Artigo recebido em dezembro/2007

Aprovado em março/2008 segundo aspecto ou o tipo de violência encontra melhores possibilidades de fundamentação do que a do primeiro. Aliás, arriscaria dizer que na ausência da "violência moral", a existência da "violência física" seria uma mera abstração. Sempre que se discute a violência como um problema social tem-se como referência a idéia do uso ilegítimo da força, ainda que freqüentemente este aspecto seja tomado como dado, fazendo com que a dimensão moral da violência seja pouco elaborada e mal compreendida, mesmo quando constitui o cerne da agressão do ponto de vista das vítimas. Pois é exatamente a esta dimensão do problema que me detenho no contexto do debate sobre a relação entre direitos, insulto e cidadania.

Nos últimos anos venho tentando compreender os atos ou eventos de desrespeito à cidadania que não são captados adequadamente pelo Judiciário ou pela linguagem dos direitos, no sentido estrito do termo. Assim, procuro apresentar o conteúdo 
desses atos por meio da noção de insulto moral, como um conceito que realça as duas características principais do fenômeno: (1) trata-se de uma agressão objetiva a direitos que não pode ser adequadamente traduzida em evidências materiais; e, (2) sempre implica uma desvalorização ou negação da identidade do outro.

Para formular a noção de insulto vali-me principalmente da idéia-valor vigente no Brasil expressa a partir da dicotomia consideração/desconsideração. Tal categoria remete a um tipo de atitude importante na definição das interações sociais e articula-se com pelo menos três tradições de reflexão sobre o tema, as quais têm marcado o desenvolvimento do meu trabalho: (a) discussão em torno da noção hegeliana de Anerkennung (reconhecimento) e da sua ausência expressa na idéia de Mißachtung (desrespeito, desatenção), retomada contemporaneamente nos trabalhos de Taylor (1994) e Honneth (1996); (b) debate francês sobre considération (e seu oposto, déconsidération), que remonta a Rousseau e que alguns desdobramentos recentes diretamente relacionados com meu foco de interesse foram reunidos numa publicação de Haroche e Vatin (1998), em que o tratamento relativo à consideração é definido como um direito humano; e, (c) discussões associadas à noção maussiana de dádiva ou reciprocidade, assim como têm sido articuladas pelo grupo da Revue du M.A.U.S.S., especialmente nos trabalhos de Caillé (1998) e Godbout (1992, 1998). ${ }^{1}$

Desse modo, analiso a relação entre as idéias de respeito a direitos plenamente universalizáveis, tendo como referência o indivíduo genérico, e de consideração ao cidadão, portador de uma identidade singular. Tenho examinado essa relação em três contextos etnográficos distintos - no Brasil, no Canadá (Quebec) e nos Estados Unidos - por meio da análise de conflitos e de eventos políticos que envolvem afirmação de direitos ou demandas por reconhecimento. A articulação entre as dimensões legal e moral dos direitos ou da cidadania encontra-se então no primeiro plano da pesquisa nesses três países. Tanto nos processos de resolução de disputas no âmbito dos Juizados de Pequenas Causas em Massachusetts, como no debate público sobre a soberania do Quebec, ou nas discussões sobre direitos quando da elaboração da Constituição de 1988 e nas reformas que se seguiram no processo de redemocratização do Brasil, as idéias de respeito e consideração mostraram-se fecundas para a compreensão dos fenômenos. O insulto moral revelou-se um aspecto importante dos conflitos nos três contextos etnográficos e, em vista de sua aparente "imaterialidade", tendia a ser invisibilizado como uma agressão que merecesse reparação.

Apesar de o insulto moral aparecer com características próprias e implicações diversas em cada contexto etnográfico, está freqüentemente associado à dimensão dos sentimentos, cuja expressão desempenha um papel importante em sua visibilidade. Nesse sentido, o material etnográfico estimulou indagações sobre a expressão ou a evocação dos sentimentos e a mobilização das emoções dos atores na apreensão do significado social dos direitos, cujo exercício demanda uma articulação entre as identidades dos concernidos. Trata-se de direitos acionados em interações que não podem chegar a bom termo por meio de procedimentos estritamente formais e que requerem esforços de elaboração simbólica da parte dos interlocutores para viabilizar o estabelecimento de uma conexão substantiva entre eles, permitindo o exercício dos respectivos direitos (Cardoso de Oliveira, 2004a, pp. 81-93). A atitude de distanciamento ou a ausência de deferência ostensiva situadas no pólo oposto desta conexão, quando percebidas como constituindo um ato de desconsideração, provocam o ressentimento ou a indignação do interlocutor, característicos da percepção do insulto.

Neste empreendimento, a fenomenologia do fato moral assim como proposta por Strawson, acionando a experiência do ressentimento, pareceme particularmente apropriada para caracterizar o lugar dos sentimentos na percepção do insulto, dando visibilidade a este tipo de agressão, e sugerindo uma distinção importante entre ato e atitude ou intenção para a apreensão do fenômeno:

\footnotetext{
Se alguém pisa na minha mão acidentalmente, enquanto tenta me ajudar, a dor não deve ser menos aguda do que se pisasse num ato de desconsideração ostensiva à minha existência, ou com um desejo malévolo de me agredir. Mas deverei normalmente sentir, no segundo caso, um tipo e um grau de ressentimento que não sentiria no primeiro [...] (Strawson, 1974, p. 5).
}

Ainda segundo Strawson, o ressentimento da vítima nesse tipo de situação provocaria um sentimento de indignação moral em terceiros que tivessem presenciado o ato e capitado a intenção do agressor, dando assim substância ao caráter objetivo da agres- 
são. Evidentemente, quando falamos em sentimentos no plano moral, dirigimo-nos àqueles sentimentos social ou intersubjetivamente compartilhados.

$\mathrm{O}$ insulto aparece então como uma agressão à dignidade da vítima, ou como a negação de uma obrigação moral que, ao menos em certos casos, significa um desrespeito a direitos que requerem respaldo institucional. Tomada como o resultado da transformação da noção de honra na passagem do antigo regime para a sociedade moderna (Berger, 1983; Taylor, 1994), a dignidade é caracterizada como uma condição dependente de expressões de reconhecimento, ou de manifestações de consideração, cuja negação pode ser vivida como um insulto pela vítima, percebido como tal por terceiros. Esta formulação tem sido aprimorada pelo diálogo com abordagens que enfocam a dádiva ou as relações de reciprocidade (ver La Revue du M.A.U.S.S.), o qual me permitiu caracterizar direitos que dão precedência ao elo social e que colocam em segundo plano a dimensão dos interesses individuais ou a idéia de direitos intrínsecos ao indivíduo. Assim, sugiro que o reconhecimento poderia ser concebido como a outra face do hau do doador na elaboração de Marcel Mauss sobre as trocas recíprocas; e argumento que a sua expressão constituiria uma das três dimensões temáticas presentes em quase todos os conflitos que desembocam no Judiciário:

(1) a dimensão dos direitos vigentes na sociedade ou comunidade em questão, por meio da qual é feita uma avaliação da correção normativa do comportamento das partes no processo em tela; (2) a dimensão dos interesses, por meio da qual o judiciário faz uma avaliação dos danos materiais provocados pelo desrespeito a direitos e atribui um valor monetário como indenização à parte prejudicada, ou estabelece uma pena como forma de reparação; e, (3) a dimensão do reconhecimento, por meio da qual os litigantes querem ver seus direitos de serem tratados com respeito e consideração sancionados pelo Estado, garantindo assim o resgate da integração moral de suas identidades (Cardoso de Oliveira, 2004b, p. 127).

A caracterização do insulto como uma agressão moral, de difícil tradução em evidências materiais, trouxe à tona uma dimensão dos conflitos freqüentemente mal equacionada pelos atores em sociedades complexas, modernas (contemporâneas), onde vigora o direito positivo. Seja devido à grande dose de impermeabilidade do Judiciário a demandas de reparação por insulto, como demonstra a análise de pequenas causas nos Estados Unidos (Cardoso de Oliveira, 1989, 1996a, 1996b, 2002); seja devido à dificuldade de formular um discurso adequado para fundamentar direitos não universalizáveis, como sugere a resistência do Canadá anglófono às demandas por reconhecimento do Quebec como uma sociedade distinta (Idem, 2002); ou ainda seja devido aos constrangimentos para a universalização do respeito a direitos básicos de cidadania no Brasil, em vista da dificuldade experimentada pelos atores em internalizar o valor da igualdade como um princípio para a orientação da ação na vida cotidiana (Idem, ibidem).

A propósito, essa dificuldade brasileira induziu-me a propor uma distinção entre esfera e espaço públicos, como duas dimensões da vida social, vigentes nas sociedades modernas de uma maneira geral, mas que no Brasil teriam a peculiaridade de apresentarem-se de forma desarticulada. Enquanto a esfera pública englobaria "o universo discursivo onde normas, projetos e concepções de mundo são publicizadas e estão sujeitas ao exame ou debate público" (Idem, 2002. p. 12), seguindo Habermas, o espaço público é caracterizado "como o campo de relações situadas fora do contexto doméstico ou da intimidade onde as interações sociais efetivamente têm lugar" (Idem, ibidem). Tal noção de espaço público tem um campo semântico em alguma medida similar ao definido por DaMatta em relação ao mundo da rua, mas procura realçar um padrão de orientação para a ação que combinaria a perspectiva da impessoalidade com uma atitude hierárquica em face do mundo, trazendo para o cotidiano dos atores o que Kant de Lima define como "paradoxo legal brasileiro" (1995, pp. 5663). O que salta aos olhos no caso brasileiro é a contradição entre a hegemonia das idéias liberais em prol dos direitos iguais na esfera pública e a dificuldade encontrada pelos atores em atuar de acordo com essas idéias no espaço público, onde a visão hierárquica freqüentemente teria precedência.

Uma dificuldade a mais nos três casos etnográficos estudados deve-se ao fato de o reconhecimento e a consideração não poderem ser convertidos em direitos protegidos pelo Judiciário, pois não há como fundamentar legalmente a atribuição de um valor singular a uma identidade específica, e exigir o seu reconhecimento social. As demandas por reconhecimento também não podem ser satisfeitas pela simples obediência a uma norma legal, 
na medida em que aquele que reconhece deve ser capaz de transmitir um sinal de apreço ao interlocutor - isto é, à sua identidade ou ao que ela representa. Nos casos em que o reconhecimento tornase uma questão, a ausência deste sinal é vivida como uma negação da identidade do interlocutor, que se sente agredido. É, nesse sentido, que o aspecto dialógico do reconhecimento se faz presente com todas as suas implicações. Isto também significa que o reconhecimento é uma atitude ou um direito que precisa ser permanentemente cultivado, e que as demandas a ele associadas não podem jamais ser contempladas de forma definitiva. Mesmo quando elas são plenamente satisfeitas em um determinado momento, não há garantia de que o problema não possa reaparecer no futuro.

O estudo de Juizados Especiais no Distrito Federal focaliza tanto as causas criminais como as cíveis e, neste último caso, as causas por dano moral suscitam interesse especial. A literatura sobre os Juizados tem chamado a atenção para certas características particularmente interessantes que dizem respeito à relação entre dádiva, insulto, direitos e sentimentos. Assim como em minha pesquisa sobre Juizados de Pequenas Causas nos Estados Unidos, os Juizados no Brasil também parecem impor às causas que lhe são encaminhadas um forte processo de filtragem, o qual tende a excluir aspectos significativos do conflito vivido pelas partes, reduzindo substancialmente a perspectiva de um equacionamento adequado para suas demandas e preocupações. Desse modo, apesar de os litigantes terem a oportunidade de resolver suas disputas por meio da conciliação ou de uma transação penal antes de terem suas causas avaliadas pelo juiz numa audiência de instrução e julgamento, as duas primeiras não constituem etapas ou possibilidades verdadeiramente alternativas à audiência judicial, pois parecem orientar-se pela mesma lógica de equacionamento exclusivamente jurídico das disputas. Enquanto nos Estados Unidos os serviços de mediação costumam viabilizar a discussão de problemas que não têm espaço nas audiências judiciais, ainda que freqüentemente não consigam contemplar as demandas dos atores em relação à reparação por insulto, no Brasil a conciliação e/ou a transação penal procuram produzir acordos que representam uma obediência estrita à lógica judicial, com o agravante de não manter a mesma preocupação com os direitos das partes ao devido processo legal, sendo sistematicamente descritos como procedimentos de caráter impositivo.

Assim, a filtragem das causas começa no balcão do juizado, quando o autor tem sua causa "reduzida a termo" pelos funcionários que enquadram a demanda em categorias jurídicas e encaminham administrativamente as causas. Em vez de atentar para a perspectiva dos litigantes na disputa, os procedimentos de conciliação parecem procurar convencer as partes sobre a precedência da lógica judicial e dos constrangimentos que impediriam qualquer equacionamento de outra ordem (Kant de Lima et al., 2003, pp. 19-52). Na mesma direção, Alves fala de "acordos forçados" em sua pesquisa sobre os Juizados Cíveis no Paranoá (2004, pp. 104-108), confirmando relatos que me foram feitos por alunos de direito estagiando em Juizados Especiais, segundo os quais esta atitude impositiva seria muito freqüente entre os conciliadores dos Juizados. Ao vestirem uma pelerine, os conciliadores assumem plenamente o papel de autoridades e acentuam ainda mais a distância em relação às partes. ${ }^{2}$

Nesse sentido, é necessário investigar melhor, com mais detalhe, a visão dos litigantes sobre o modo pelo qual suas causas são processadas no Juizado, e em que medida eles vêem seus direitos, interesses e preocupações contemplados ao longo da tramitação da causa ou no desfecho no âmbito da instituição. Há sinais de que as diferenças entre conciliação, transação penal e audiência de instrução e julgamento nem sempre são inteiramente claras para as partes (Gomes de Oliveira, 2005), e seria interessante indagar sobre os significados atribuídos à negociação nas duas primeiras modalidades de encaminhamento e ao julgamento do juiz na última delas. Confirmando-se o aparente descompasso entre a perspectiva dos litigantes e a dos operadores do direito, como estes justificariam o padrão de tratamento dado às causas no Juizado, e como perceberiam o significado dos aspectos das disputas excluídos do processo por meio da prática de reduzir a termo?

Aliás, o que o Judiciário costuma deixar de fora são todos aqueles aspectos das disputas associados à dimensão temática do reconhecimento, conforme definido acima. Como procurar-se-á demonstrar em seguida, além de inviabilizar a compreensão das causas onde o reconhecimento tem um lugar significativo, o Judiciário acabaria colaborando para o eventual agravamento destes con- 
flitos. Na mesma direção, o material etnográfico não apenas chama a atenção para a importância da dimensão moral dos direitos, mas sugere também que talvez não seja adequado falar em violência quando não houver agressão de ordem moral, dando sentido ao aparente paradoxo de que a "violência física", sem um componente simbólico/moral, seria apenas uma abstração, invertendo, de fato, a equação entre os pares material/simbólico, de um lado, e objetivo/subjetivo, de outro. A discussão de Simião (2005) sobre "violência doméstica" no Timor Leste é particularmente contundente em relação à precedência da dimensão simbólico-moral na constituição da violência. Entretanto, vale à pena abordar outros exemplos para caracterizar melhor a problemática do insulto antes de concluir com o exemplo do Timor Leste.

São conhecidas as críticas à atuação dos Juizados Especiais Criminais (Jecrims) brasileiros nos casos que envolvem agressões à mulher e a negociação de penas alternativas. Além da alta incidência e reincidência de casos de mulheres que são repetidamente agredidas por seus companheiros e não encontram nos tribunais uma proteção adequada, o modo pelo qual suas causas são equacionadas nos Juizados dirige-se exclusivamente à dimensão física da agressão, deixando inteiramente de lado o aspecto moral que, de certo modo, machuca mais e tem conseqüências mais graves. ${ }^{3}$ Refiro-me ao processo de desvalorização da identidade da vítima, levada a assumir a condição de total subordinação às idiossincrasias (agressivas) do companheiro. O discurso da perda da identidade é recorrente, e os direitos agredidos neste plano não encontram respaldo no processo de resolução de disputa no âmbito do Judiciário. Embora os processos de conciliação e de transação penal critiquem, às vezes com veemência, as agressões do companheiro, há forte pressão para o acordo ou para a aceitação da pena alternativa negociada, sem que seja elaborado de forma adequada o significado moral da agressão sofrida. Isto é, esta dimensão não é nem abordada, o que inviabiliza sua reparação, dado que a sua percepção ou sanção não pode ser automaticamente embutida no acordo, transação penal ou decisão focada apenas no aspecto físico da agressão.

Pois, se a ocorrência do insulto demanda esforços de elaboração simbólica para ganhar inteligibilidade, a sua reparação freqüentemente demandaria ainda processos de elucidação terapêutica do ponto de vista da vítima. Não me refiro a processos terapêuticos em sentido estrito, como um padrão, mas à necessidade de repor os déficits de significado provocados por agressões arbitrárias, vividas como uma negação do eu ou da persona da vítima, e cujo caráter normativamente incorreto e merecedor de sanção social negativa tem que ser internalizado pela vítima para que sua identidade de pessoa moral, digna de estima e consideração, seja resgatada. Como tem sido assinalado na literatura sobre o problema do pagamento de cestas básicas como pena alternativa, que pode até mesmo punir as vítimas de baixa renda, uma vez que retira recursos significativos de sua unidade doméstica, a sanção não guarda nenhuma relação com o aspecto moral da agressão. Além disso, há relatos de que o próprio cumprimento da pena poderia ser entendido como um agravante da agressão moral à vítima, como nos "vários casos de autores chegarem no cartório com o comprovante de pagamento da cesta e dizendo que se ele soubesse que seria tão barato bater na mulher, ele bateria mais vezes" (Beraldo de Oliveira, apud G. Debert, 2002). Tal afirmação, que provavelmente é repetida na frente da vítima, imputa a ela a condição de um mero objeto, sujeito às idiossincrasias do agressor.

Entretanto, os casos de agressão à mulher são apenas os mais conhecidos e os mais numerosos atendidos pelos Jecrims. Problemas similares ocorrem em causas envolvendo demandas do consumidor, ou em conflitos entre vizinhos e parentes, cujo potencial para desembocar em crimes graves é muito maior do que geralmente se imagina. Isto é, se levarmos em conta dados recentemente publicados pelo Núcleo de Estudos da Violência da USP, indicando que 38\% das agressões com arma de fogo em Salvador e no Distrito Federal, por exemplo, são protagonizadas por conhecidos, companheiros ou familiares (Peres, 2004, p. 29). ${ }^{4}$ No que concerne aos conflitos do consumidor, Ciméa Bevilaqua relata vários casos nos quais o sentimento de terem sido desrespeitados por fornecedores é um aspecto central das causas encaminhadas por consumidores. Em uma delas, após ter seu pleito comercial plenamente contemplado pelo fornecedor, o consumidor só concorda com o acordo negociado na frente do delegado quando o fornecedor se dispõe a pedir desculpas formais a ele (Bevilaqua, 2001, p. 319). O componente moral das disputas, aqui expresso pela percepção do insulto, 
pode ganhar amplitude surpreendente, como no conflito entre Anselmo, Denílson e Natalício, descrito por Gomes de Oliveira (2005, pp. 90-93) em sua etnografia sobre Jecrims na cidade do Gama, em Brasília.

A rigor, trata-se de conflitos sistematicamente repetidos entre estes três vizinhos, que vêm se agravando ao longo do tempo com a colaboração do Judiciário, não encontrando um caminho adequado para equacionar as respectivas disputas. ${ }^{5}$ Apesar de esses conflitos compartilharem muitos dos problemas identificados por Gomes de Oliveira em outras causas que chegam aos Juizados, não deixa de ser curioso o fato de o Judiciário neste caso se mostrar incapaz de lidar com a seqüência de problemas entre as partes - um promotor (MP), por exemplo, sugeriu que um dos envolvidos mudasse de endereço como forma de solucionar o problema! (Idem, p. 90), conselho aparentemente seguido por Denílson que não mora mais lá. Os três personagens são pessoas de classe média baixa e residem em casas vizinhas que compartilham a área verde em frente aos seus terrenos. Tal área não pode ser cercada e, embora seja considerada área de transito livre, não deixa de representar projeções associadas a cada terreno, conforme padrão generalizado em Brasília, emprestando certa ambigüidade a seu status no que concerne aos direitos das partes e ocupando lugar de destaque nos conflitos entre elas. Anselmo é pintor autônomo de carros, tem 38 anos, reside com a companheira e não tem filhos; Natalício tem 25 anos, está desempregado e reside com a mãe e os irmãos; Denílson tem 30 anos, morava com a mãe na época dos conflitos e, atualmente, está residindo com a esposa em outra localidade.

O primeiro incidente relatado por Gomes de Oliveira envolve Anselmo e Denílson, e teria sido detonado pela iniciativa de Anselmo de plantar árvores na área verde sem respeitar os limites de sua projeção. A mãe de Denílson não gosta da idéia e pede ao filho que solicite a retirada das árvores. Ao falar com Anselmo, Denílson avisa que ele mesmo retiraria as árvores caso o outro não o fizesse. Anselmo toma a ameaça como uma ofensa, deixa tudo como está, e Denílson tira as árvores plantadas na área verde associada ao seu terreno. Anselmo fica irado com essa atitude, prepara um coquetel molotov e o arremessa contra o carro de Denílson após pular o muro de sua residência. É então processado pelos danos ao carro e condenado a inde- nizar Denílson, além de ter que prestar serviços à comunidade como pena alternativa. Embora reconheça a responsabilidade pelos estragos no carro, fica inconformado por não ter podido apresentar sua demanda em relação às árvores arrancadas, já que o juiz teria se recusado a ouvi-lo, e não consegue entender a lógica do Juizado:

[...] um cara que rancou casca de uma árvore foi preso [referindo-se à notícia de um camponês preso por ter arrancado casca de árvore protegida para fazer chá (LRCO)], eu vejo o cara quebrando uma árvore aqui não é crime, eu fui lá, fiz minha justiça, porque achei que se eu fosse lá e fizesse minha justiça o cara não ia mais mexer comigo, o juiz vai me obrigar a pagar o carro, me obriga a prestar serviços à comunidade, mas não obriga o cara a replantar as árvores (Idem, p. 92).

Além de reclamar da recusa do juiz, que lhe havia sugerido dar entrada em outro processo, Anselmo interpreta a pressa do Juizado como sinal de indiferença e arbitrariedade de uma decisão sem sentido, afirmando: "Eu me senti um Zé ninguém, uma pessoa pequena, diminuída [.. .]" (Idem, p. 92). Anselmo alega que deveria ter direito à reparação por danos morais e sugere, em sua fala, que a motivação para fazer a sua justiça estava associada à tentativa de fazer com que Denílson não mexesse mais com ele. Isto é, não o desrespeitasse ou não o desconsiderasse mais. Como nenhuma de suas alegações recebera atenção do Juizado, Anselmo não apenas fica insatisfeito com o resultado, mas também concebe seu conflito com Denílson como uma questão em aberto, sujeita a ser retomada a qualquer momento.

No segundo episódio envolvendo Anselmo, a disputa é com Natalício, mas a lógica do Juizado continua igualmente distante da perspectiva das partes. Agora os dois litigantes alegam terem sofrido ameaças de parte a parte, e o juiz condena ambos a pagarem cestas básicas como pena alternativa. Os dois saem insatisfeitos do Juizado e Natalício faz críticas similares às que Anselmo havia feito anteriormente, indicando contrariedade com a falta de espaço para discutir o caso. Como alega não ter condições de pagar as cestas básicas por estar desempregado, fica sujeito a uma eventual ordem de prisão do juiz. Assim como no primeiro episódio, o encaminhamento dado ao conflito no Juizado mantém a questão em aberto entre as partes, o que sugere a possibilidade de que as ameaças se trans- 
formem em agressões mais graves no futuro. $\mathrm{O}$ foco do Juizado na "redução a termo" das disputas, filtrando apenas a dimensão estritamente legal dos conflitos, talvez permita pensarmos numa certa fetichização do contrato - como categoria englobadora das prescrições jurídicas de todo tipo -, característica do direito positivo, em que o espaço para articular demandas é limitado ao que está estipulado no contrato e no código penal (ou civil), como prescrições autocontidas, auto-suficientes e abrangentes o bastante para equacionar os conflitos que chegam ao Judiciário. Assim, a dimensão moral dos direitos é totalmente descartada de qualquer avaliação, e relações entre pessoas, portadoras de identidade, são pensadas como relações entre coisas ou autômatos com interesses e direitos prescritos, mas sem sentimentos, autonomia ou criatividade.

Problemas desta ordem não são vividos com dramaticidade apenas nos Jecrims ou por litigantes como Anselmo, Denílson e Natalício, mas parecem representar um padrão de dificuldade para lidar com direitos associados à dimensão moral das disputas, característico de tribunais onde vigora o direito positivo, ou de instituições orientadas pela mesma lógica, em diversas partes do mundo. Relatos sobre a Comissão de Verdade e Conciliação estabelecida na África do Sul para lidar com as atrocidades do apartheid ou o debate em torno da paranóia do querelante na Austrália são bons exemplos da abrangência do problema e da pluralidade de situações onde a invisibilidade dos respectivos direitos aos olhos do Judiciário e a importância do seu equacionamento do ponto de vista das partes emergem de maneira muito forte.

Em uma análise interessante e criativa sobre justiça transicional em três países africanos que passaram por regimes opressivos ou situações de guerra civil, Simone Rodrigues (2004) apresenta um material particularmente estimulante sobre a Comissão de Verdade e Reconciliação instalada na África do Sul no período pós-apartheid. Sob a liderança do Reverendo Desmond Tutu, a Comissão foi instalada como alternativa aos tribunais judiciais que vinham julgando os crimes ocorridos durante o apartheid, inclusive aqueles que teriam sido cometidos pelo Congresso Nacional Africano. A Comissão realizava sessões públicas televisivas em canal aberto e mobilizou a sociedade. Uma de suas características centrais, e que gerou muitas críticas no início dos trabalhos, era o fato de que todos aqueles que se dispusessem voluntariamente a contar toda a verdade sobre os crimes políticos (em sentido amplo) que teriam cometido durante o apartheid seriam anistiados pela Comissão. Os depoimentos eram realizados na presença das vítimas (quando vivas) ou de seus parentes e advogados, que poderiam fazer perguntas ao criminoso confesso. Com a possibilidade de anistia, a ênfase do procedimento não estava na punição dos culpados ou responsáveis, mas na restauração da harmonia social, expressa por meio da categoria nativa Ubuntu. Além do caráter catártico dos depoimentos para vítimas e agressores, o desvendamento de eventos carregados de simbolismo e emoção para as partes, em um contexto institucional muito significativo e amplamente compartilhado pela sociedade como um todo, acabou tendo um forte componente terapêutico, viabilizando a reparação de ofensas e sofrimentos que, segundo os atores, uma condenação judicial jamais teria realizado.

Há muitos relatos de parentes das vítimas nos quais a oportunidade de tomar conhecimento sobre o que teria de fato ocorrido quando do desaparecimento, ou assassinato, de seus entes queridos é descrita como uma experiência de alivio e de reestruturação da identidade da maior relevância. Além da superação da angústia viabilizada pelo acesso à informação, as condições em que o processo se dá permitem uma reelaboração da perda ou da agressão num novo patamar de inteligibilidade, renovando o significado da experiência e da inserção social das partes. Desse modo, ao permitir que a experiência de agressão seja revivida com maiores esclarecimentos e possibilidades de mobilizar as emoções para restabelecer uma conexão plena com os eventos vividos no passado, e contando com o apoio institucional adequado, a Comissão seria um bom exemplo dos processos de elucidação terapêutica mencionados acima. Em poucas palavras, o processo de (re)discussão dos crimes do apartheid no âmbito da Comissão, dramatizado nos depoimentos e na busca por esclarecimento dos atores, cuja indignação e eventual arrependimento (dos agressores) são "ritualmente" sancionados pelo Estado, produz uma ressimbolização da experiência das partes e a renovação de suas identidades como pessoas morais, dignas do respeito e da consideração que haviam perdido.

Mas, se o exemplo da África do Sul revela possibilidades efetivas de reparação para o insulto 
de ordem moral, a discussão sobre a paranóia do querelante na Austrália indica a dificuldade que as instituições modernas têm para lidar com este tipo de agressão. Os dados australianos foram retirados da edição de abril de 2004 do British Journal of Psychiatry, que traz os resultados de pesquisa realizada sobre o tema por um grupo de psiquiatras australianos. Segundo eles, a paranóia do querelante já teria ocupado um lugar de destaque na literatura, mas teria caído em descrédito na primeira metade do século XX, "atacada por críticas de que não fazia mais do que patologizar aqueles com energia e disposição para defender seus direitos" (Lester $e t$ al. 2004, pp. 352-356). A pesquisa foi feita em seis escritórios de Ouvidores, com o auxílio de profissionais experientes no encaminhamento de reclamações apresentadas por cidadãos, cuja primeira tentativa de resolver seus problemas nas mais diversas instituições e tipos de atividade (governo, negócios, serviços) havia fracassado. Esses profissionais da ouvidoria foram solicitados a preencher questionários sobre reclamantes especialmente persistentes, cujos casos já haviam sido arquivados. Cada vez que um caso fosse identificado, os profissionais selecionavam, como controle, o próximo caso nos arquivos apresentado por pessoa do mesmo gênero e faixa etária, cuja reclamação era similar em linhas gerais. Entre os 110 casos selecionados 96 tiveram seus questionários respondidos, sendo que 52 correspondiam a reclamantes persistentes e 44 aos casos de controle. Setenta e dois por cento dos persistentes eram homens que, num universo equilibrado de acordo com o gênero, indicava uma super-representação de homens no grupo persistente. O material foi classificado segundo muitas variáveis comportamentais e constitui uma rica fonte de análise a ser desenvolvida em várias direções. Em um manuscrito ainda inédito, comparo de forma mais detalhada este material com dados etnográficos do Brasil e dos Estados Unidos e sugiro que, ao não conseguir entender adequadamente demandas de reparação por insulto, o Judiciário tende a interpretá-las como produto de alguma deficiência mental dos reclamantes. ${ }^{6}$ No momento, gostaria apenas de salientar alguns dados que ajudam a caracterizar substancialmente a percepção do insulto do ponto de vista dos atores e a amplitude de causas onde ele se faz presente, sem deixar de identificar características excepcionais que sugerem a existência de problemas psicológicos mais agudos entre os reclamantes.

\section{Quadro Comparativo entre Reclamantes Persistentes e Controles}

\begin{tabular}{lll}
\hline Indicadores de Perspectiva ou Comportamento & Persistentes & Controles \\
\hline Assinalan danos à auto-estima & $40 \%$ & $12 \%$ \\
\hline Querem desculpas por mal-trato & $67 \%$ & $32 \%$ \\
\hline Justiça baseada em princípios & $60 \%$ & $18 \%$ \\
\hline Querem vingança & $43 \%$ & $11 \%$ \\
\hline Querem "to have their day in court" & $29 \%$ & $04 \%$ \\
\hline Fazem ameaças ao telefone ou em pessoa & $52 \%$ & $00 \%$ \\
\hline
\end{tabular}

Como mostra o quadro, todas as variáveis selecionadas indicam aspectos que demonstram o envolvimento pessoal dos reclamantes com suas causas e trazem à tona dimensões da reclamação que não se resumem a demandas por reparação de interesses ou de direitos impessoais, totalmente dis- sociados da identidade do reclamante. Ainda que haja diferenças significativas entre as duas colunas, é interessante notar que, com exceção da última variável - "fazer ameaças ao telefone ou em pessoa" -, todas as demais também aparecem com alguma intensidade na coluna dos Controles. Neste 
aspecto, enquanto as três primeiras variáveis fazem uma forte associação entre direito e identidade - e sua relevância também seria facilmente demonstrada nos casos discutidos anteriormente -, as três últimas refletem com maior ênfase a necessidade das partes em confrontar as agressões alegadas para superar o problema e resgatar suas identidades ou o sentido que atribuem à cidadania. A propósito, se a quarta e a sexta variáveis expressam uma atitude agressiva diante do problema, a demanda de "ter seu dia no tribunal" (to have their day in court) constitui uma expressão de duplo sentido no mundo anglo-saxão: de um lado caracteriza o direito de todo cidadão, como pessoa moral, ter seus direitos respeitados e suas reclamações ouvidas pelo Estado; de outro, é utilizada para assinalar uma certa condescendência institucional para com aqueles litigantes cujo comportamento ou argumentos não fazem muito sentido do ponto de vista do tribunal, mas fazem questão de exercer o direito de serem ouvidos pelo juiz.

Em qualquer hipótese, embora seja inegável o caráter excessivo de alguns comportamentos de litigantes classificados como persistentes, há uma continuidade com os casos-controle nos quais os atores demonstram sensibilidade ao insulto. Mais do que uma dimensão paranóica, os reclamantes persistentes chamam a atenção para as dificuldades das instituições judiciárias ou congêneres em lidar com o insulto, assim como para o significado social desse tipo de agressão. Aliás, como discuto no manuscrito supracitado (ver nota 7), o fenômeno descrito como querulous paranoia no British Journal of Psychiatry é muito mais abrangente do que parece à primeira vista, e poderia ser mais bem compreendido a partir da problemática do insulto.

Para concluir, gostaria de fazer menção ao trabalho de Simião (2005) sobre o Timor Leste, que mostra como o descrédito em relação à dimensão moral da violência teria marcado o processo de "invenção da violência doméstica" como um problema social contemporâneo. Tradicionalmente, os timorenses concebiam várias situações em que bater na mulher e nos filhos, ou eventualmente apanhar da mulher nas mesmas circunstâncias, tinha um aspecto pedagógico. Bater para corrigir problemas de comportamento seria uma atitude legítima entre marido e mulher ou entre pais e filhos, desde que fosse feito com moderação. Ainda hoje, discursos legitimando o bater pedagógico encontram respal- do de homens e mulheres em vários lugares no Timor. Entretanto, a forte atuação de ONGs e organismos internacionais no combate a essas práticas, sem qualquer esforço para compreender o seu sentido local, tem mudado este quadro. Os programas de combate à "violência doméstica" instituídos pelo Estado sob forte influência do discurso universalista (e por vezes sociocêntrico) em defesa dos direitos humanos e da igualdade de gênero, sem as mediações necessárias para ajustar o discurso ao contexto local, têm tido algum êxito na proteção das mulheres contra este novo tipo de agressão, mas têm também criado novos impasses, confusões e ambigüidades. Com a criminalização das agressões (físicas) à mulher em sentido amplo, foram inviabilizados, em grande medida, os procedimentos tradicionalmente acionados para o equacionamento desse tipo de conflito, que em muitas circunstâncias respondem melhor às demandas das partes. ${ }^{7}$ Trata-se de um processo complexo e rico em implicações bem abordadas no trabalho de Simião, o que me leva a fazer três observações no sentido de enfatizar a importância da precedência simbólico-moral da violência para uma melhor compreensão do fenômeno.

Em primeiro lugar, se atentarmos para o ponto de vista dos atores e para o contexto de referência de suas representações, verificaremos que a agressão física do passado, legitimada socialmente por meio de seu sentido pedagógico, passa a ser caracterizada como um ato de violência, recriminado socialmente, no momento em que seu conteúdo pedagógico perde vigência e o ato passa a ser interpretado como uma agressão à identidade da vítima. Enquanto o bater tinha uma justificativa moral e o sofrimento da vítima era essencialmente físico, a prática era não só aceita, mas também defendida por homens e mulheres, que se limitavam a criticar os excessos. Não obstante, quando o bater se constitui numa nova forma de agressão, dirigida à pessoa da vítima e representada como um desrespeito ou negação de sua identidade como pessoa moral, a agressão ganha ares de "violência doméstica" e passa a ser intolerável. Essa mudança aparece claramente na descrição que Simião faz do caso da timorense que durante onze anos apanhara do marido sem que isto fosse um problema na relação, até o momento em que ela passou a conviver com estrangeiros no escritório local da Cruz Vermelha, onde trabalhava; para surpresa do marido, decidiu 
pedir divórcio. Segundo Simião, "à dor física que ela sentiu durante anos agora se somava a uma dor moral. O sentido do ato de agressão mudara, mudando, com isso, as suas conseqüências" (2005, p. 94). Indagando sobre o caso, o autor descobre que "a mulher agora envergonhava-se por apanhar do marido" (Idem, p. 95). Se a dor física havia sido plenamente suportável durante anos, a vergonha e a humilhação eram intoleráveis. ${ }^{8}$

Um segundo aspecto da precedência simbólico-moral na compreensão da violência também presente no caso do Timor refere-se a situações nas quais, ante a ausência de agressão física, não se percebe o sofrimento provocado pelo insulto, por mais que o problema seja verbalizado. Assim, se bater é um ato sujeito a conotações múltiplas na cultura local, ser obrigada pelo marido a obedecêlo contra a sua vontade é considerado um insulto grave: "uma ofensa ao direito que a mulher tem de ter a sua opinião e sua vontade respeitadas dentro de casa - desde que, evidentemente, sua vontade não implique o abandono de seus deveres" (Idem, p. 236). Tomar uma segunda esposa sem consultar ou obter o apoio da primeira seria um bom exemplo do tipo de violência percebida como grave pela população e ocultada no discurso da igualdade de gênero (Idem, p. 237). De certo modo, como sugerido na introdução deste trabalho, esse segundo tipo de violência, simbólico-moral, teria sua objetividade mais bem fundamentada do que a primeira, estritamente associada à agressão física.

Finalmente, para evitar qualquer tipo de sociocentrismo em relação ao Timor Leste, vale lembrar que em 2004 a Suprema Corte do Canadá avaliou uma ação de inconstitucionalidade que contestava o direito de pais e mestres baterem pedagogicamente nas crianças, e pronunciou-se positivamente, reafirmando este direito desde que houvesse moderação nesse sentido. Seria adequado falar em violência neste caso? Ou, em qualquer outro que tivesse como referência agressões consideradas legítimas?

\section{Notas}

1 Uma quarta vertente desse debate tem como referência o trabalho de Carol Guilligan - In a different voice (1982/1993) —, que contrapõe o foco na obediência a regras e na idéia de separação, característica das teorias de desenvolvimento moral, e predominante entre homens, a precedência atribuída à relação no equaciona- mento dos mesmos problemas, e que seria mais comum entre as mulheres. Esta perspectiva tem sido retomada na análise de disputas jurídicas nos Estados Unidos (Conley e O’Barr, 1990, 1998).

2 Uma pesquisa realizada por Júlia Brussi em três Juizados Especiais Criminais no DF sugere que esta distância é característica dos Juizados freqüentados por atores de baixa renda, não tendo sido registrada no Juizado situado na área mais rica da cidade (Brussi, 2005).

3 Dois documentários na televisão (Globo Repórter) sobre o tema da "violência" contra a mulher impressionaram-me com os relatos de mulheres que após anos de sofrimento com surras, facadas e até tiros de seus companheiros haviam finalmente conseguido uma separação efetiva e tentavam reconstruir suas vidas. Mesmo nos casos em que as agressões físicas atingiam níveis absolutamente inacreditáveis, provocando longos períodos de convalescença, às vezes superiores a um ano, os relatos sobre as dificuldades de superação dos "traumas" psicológicos e de recuperação ou reabilitação da identidade agredida davam a nítida impressão de que os problemas eram mais graves. O drama da reabilitação de uma identidade distorcida após anos de sofrimento dava sinais claros sobre a importância da dimensão moral do problema.

4 Os dados em relação a outras unidades da federação são compatíveis com os especificados para Salvador e Distrito Federal, e podem ser consultados em Violência por armas de fogo no Brasil, Relatório Nacional - NEV/ USP, 2004, coordenado por Maria Fernanda T. Peres.

5 Segundo Gomes de Oliveira (2005, p. 90), Anselmo e Natalício já teriam se confrontado em várias causas inter-relacionadas no Juizado: perdas e danos, lesão corporal, ameaça, execução de sentença, penhora etc.

6 O manuscrito, intitulado "A invisibilidade do insulto: ou como perder o juízo em Juízo", foi a base de palestras proferidas na Escola Superior do Ministério Público da União em 12 de maio de 2004, e no Núcleo Fluminense de Estudos e Pesquisas - Nufep, da UFF, em 4 de agosto do mesmo ano.

7 Roberto Kant de Lima chamou minha atenção para a importância deste processo de criminalização, ao limitar ou mesmo eliminar as possibilidades de uma solução satisfatória para as partes, o qual também caracterizaria a atuação dos Jecrims no Brasil.

8 Não se trata de justificar a agressão física sob qualquer ângulo, mas de distinguir analiticamente as dimensões física e moral da agressão, sem deixar de atribuir a esta última uma precedência conceitual na definição dos atos de violência. Não só devido à dramaticidade das conseqüências objetivas a ela associadas, mas também por encontrar respaldo na experiência dos atores que, convincentemente, identificam na agressão moral uma contundência singular, totalmente ausente dos atos de agressão física em sentido estrito. 


\section{BIBLIOGRAFIA}

ALVES, J. (2004), Juizados Especiais Civeis do Paranoá: pessoalidade e impessoalidade nos intersticios do Estado. Dissertação de mestrado apresentada ao Departamento de Sociologia da Universidade de Brasília - UnB.

BERGER, P. (1983), "On the obsolescence of the concept of honor", in S. Hauerwas e A. MacIntyre (orgs.), Revisions: changing perspectives in moral philosophy, Indiana, University of Notre Dame Press.

BEVILAQUA, C. (2001), "Notas sobre a forma e a razão dos conflitos no mercado de consumo". Sociedade e Estado, XVI (1/2): 306-334.

BRUSSI, J. (2005), Observando o processo de conciliação em três Juizados Especiais Criminais do DF. Monografia de conclusão do curso de bacharelado em Ciências Sociais na Universidade de Brasilia - UnB.

CAILLÉ, A. (1998), "Nem holismo nem individualismo metodológicos: Marcel Mauss e o paradigma da dádiva". Revista Brasileira de Ciências Sociais, 38 (13): 5-37.

CARDOSO DE OLIVEIRA, L. (1989), Fairness and communication in small claims Courts. Ph.D dissertation, Harvard University, Ann Arbor, University Microfilms International (order \# 8923299).

(1996a), "Entre o justo e o solidário: os dilemas dos direitos de cidadania no Brasil e nos EUA". Revista Brasileira de Ciências Sociais, 31 (11): 67-81.

. (1996b), "Da moralidade à eticidade, via questões de legitimidade e eqüidade", in R. Cardoso de Oliveira e L. Cardoso de Oliveira, Ensaios antropológicos sobre moral e ética, Rio de Janeiro, Tempo Brasileiro (Biblioteca Tempo Universitário 99), pp. 105-142.

(2002), Direito legal e insulto moral: dilemas da cidadania no Brasil, Quebec e EUA. Rio de Janeiro, Relume Dumará.

(2004a), "Racismo, direitos e cidadania”. Estudos Avançados, 18 (50): 81-93, jan-abr.

(2004b), "Honra, dignidade e reciprocidade", in P. H. Martins, e B. F. Nunes (orgs.), A nova ordem social: perspectivas da solidariedade contemporânea, Brasília, Paralelo 15, pp. 122-135.

CONLEY, J. \& O'BARR, W. (1990), Rules versus relationships: the ethnography of legal discourse. Chicago, The University of Chicago Press.

. (1998), Just words: law, language and power. Chicago, The University of Chicago Press.

DaMATTA, R. (1979), "Você sabe com quem está falando? Um ensaio sobre a distinção entre indivíduo e pessoa no Brasil", in R. DaMatta, Carnavais, malandros e heróis, Rio de Janeiro, Zahar Editores.

DEBERT, G. (2002), "Arenas de conflitos éticos nas delegacias especiais de polícia". Trabalho apresentado no Seminário Gênero e Cidadania, realizado pelo Núcleo de Estudos de Gênero da Universidade Estadual de Campinas, 17 out. (mimeo.).

GODBOUT, J. (1998), "Introdução à dádiva". Revista Brasileira de Ciências Sociais, 38 (13): 39-51.

GODBOUT, J \& CAILLÉ, A. (1992), L'esprit du don. Quebec, Boreal.

GOMES DE OLIVEIRA, C. (2005), Saber calar, saber conduzir a oração: a administração de conflitos num Juizado Especial Criminal do DF. Dissertação de mestrado, apresentada ao Departamento de Antropologia da Universidade de Brasília - UnB.

GUILLIGAN, C. (1982/1993), In a different voice. Cambridge, Harvard University Press.

HAROCHE, C. \& VATIN, J-C. (orgs.). (1998), La considération. Paris, Deselée de Brouwer.

HABERMAS, J. (1991), The structural transformation of the public sphere. Cambridge, Mass., MIT Press.

HONNETH, A. (1996), The struggle for recognition: the moral grammar of social conflicts. Cambridge, Mass., MIT Press.

KANT DE LIMA, R. (1995), A polícia da cidade do Rio de Janeiro: seus dilemas e paradoxos. 2 ed. revista. Rio de Janeiro, Forense.

KANT DE LIMA, R.; AMORIM, M. S. \& BURGOS, M. (2003), "A administração da violência cotidiana no Brasil: a experiência dos 
Juizados Especiais Criminais", in M. S. Amorim, R. Kant de Lima \& M. Brugos (orgs.), Juizados Especiais Criminais, sistema judicial e sociedade no Brasil. Niterói, Intertexto, pp. 19-52.

LESTER, G.; WILSON, B.; GRIFFIN, L. \& MULLEN, P. E. (2004), "Unusually persistent complainants". British Journal of Psycbiatry, 184: 352356, abr.

MAUSS, M. (1925/1974), “Ensaio sobre a dádiva: forma e razão da troca nas sociedades arcaicas", in São Paulo, Edusp, pp. 37-184.

PERES, M. F. T. (2004), Violência por armas de fogo no Brasil. Relatório Nacional — NEV/USP, coordenado por Maria Fernanda T. Peres.

RODRIGUES, S. (2004), Justiça restaurativa, dialogia e reconciliação social: tribunais internacionais e comissões de verdade na África. Tese de doutorado apresentada ao Instituto Universitário de Pesquisas do Rio de Janeiro - Iuperj.

SIMIÃO, D. (2005), As donas da palavra: gênero, justiça e a invenção da violência doméstica em Timor-Leste. Tese de doutorado apresentada ao Departamento de Antropologia da Universidade de Brasília - UnB.

STRAWSON, P. (1974), "Freedom and resentment", in Freedom and resentment, and other essays, Londres, Methuen \& Co. LTD, pp. 1-25.

TAYLOR, C. (1994), "The politics of recognition", in A. Gutmann (org.), Multiculturalism and "The politics of recognition", New Jersey, Princeton University Press, pp. 25-73. 


\section{EXISTE VIOLÊNCIA SEM AGRESSÃO MORAL?}

\section{Luís Roberto Cardoso de Oliveira}

Palavras-chave: Violência; Agressão moral; Insulto; Direitos; Identidade.

Este artigo propõe a idéia de que não seria adequado classificar como violência atos de agressão que não contivessem um componente moral. Embora este último tenha um caráter eminentemente simbólico, e não material, sua objetividade como expressão de violência seria muito mais palpável do que uma agressão física em sentido estrito. A agressão moral é então definida como um insulto, que teria duas características básicas: (1) trata-se de uma agressão objetiva a direitos que não pode ser adequadamente traduzida em evidências materiais; e, (2) sempre implica uma desvalorização ou negação da identidade do interlocutor. Também é abordada a dificuldade do Judiciário em lidar com este tipo de agressão em que vigora o direito positivo, gerando insatisfação entre as partes e, às vezes, chegando mesmo a contribuir para o agravamento do conflito.

\section{IS THERE VIOLENCE WITHOUT MORAL AGGRESSION?}

\section{Luís Roberto Cardoso de Oliveira}

Keywords: Violence; Moral aggression; Insult; Rights; Identity.

The article submits that it is not adequate to classify as violence acts of aggression that do not carry a moral component. Despite having an eminently symbolic and immaterial character, such moral component would carry a much greater objectivity as an expression of violence than a physical aggression in the strict sense of the term. Moral aggressions are then defined as an insult, which convey two basic characteristics: (1) it is an objective injury to rights, which cannot be adequately translated into material evidence; and, (2) it always implies some devaluation or negation of the identity of the interlocutor. The paper also addresses the difficulties of the judiciary in dealing with such aggressions where positive law prevails, producing discontentment among the parties and often aggravating the conflict.

\section{PEUT-ON PARLER DE VIOLEN-} CE SANS AGRESSION MORALE?

\section{Luís Roberto Cardoso de Oliveira}

Mots-clés: Violence; Agression morale; Insulte; Droits; Identité.

L'article défend l'idée qu'il ne serait pas adéquat de classifier les actes d'agression qui n'ont pas une composante morale comme étant de la violence. En dépit d'un caractère éminemment symbolique et non matériel, leur objectivité comme une expression de la violence serait beaucoup plus palpable que celle d'une agression physique au sens strict. L'agression morale est alors définie comme une insulte, qui aurait deux caractéristiques fondamentales : (1) il s'agit d'une agression objective, qui ne peut être adéquatement traduite en évidences matérielles; et, (2) elle implique toujours en une dévalorisation ou une négation de l'identité de l'interlocuteur. L'article aborde également les difficultés du pouvoir judiciaire à traiter ce genre d'agression dans laquelle le droit positif prévaut, ce qui produit une grande insatisfaction et qui, parfois, contribue à aggraver le conflit. 